\title{
Dietary patterns for meals of Brazilian adults
}

\author{
Roberta de Oliveira Santos ${ }^{1}$, Regina Mara Fisberg ${ }^{1}$, Dirce Maria Lobo Marchioni ${ }^{1}$ and \\ Valéria Troncoso Baltar ${ }^{2}$ \\ ${ }^{1}$ Department of Nutrition, School of Public Health, University of Sao Paulo, Cerqueira César, São Paulo, SP 01246-904, Brazil \\ ${ }^{2}$ Department of Epidemiology and Biostatistics, Institute of Collective Health, Federal Fluminense University, Travessa Marquês \\ de Paraná, Niterói, RJ 24030-210, Brazil
}

(Submitted 21 January 2015 - Final revision received 24 May 2015 - Accepted 5 June 2015 - First published online 29 July 2015)

\section{Abstract}

The use of dietary patterns (DP) in nutritional research is well established; however, only a few studies of DP according to specific meals have been conducted. The purpose of this study was to identify the DP regarding breakfast, lunch and dinner meals of the population (aged 20 years and older of both sexes) that participated in the Health Care Survey of Sao Paulo. Food intake was estimated by using the Multiple Source Method - considering two 24-h dietary recalls. On the basis of the food groups for each meal, a factor analysis, with a principal component estimation, was applied (varimax rotation) in order to derive the DP. Prevalences of meal skipping were $5.6 \%$ for breakfast, $3.6 \%$ for lunch and $12 \cdot 8 \%$ for dinner. The findings revealed three breakfast DP: healthy, traditional and snack; five lunch DP: traditional, salad, sweetened juice, Western and meats; and four dinner DP: coffee with milk and bread, transitional, traditional, and soup and fruits. The results of this study indicate that the DP identified in accordance with the meal nicely discriminates food intake, emphasising peculiarities that are not found in global analyses and might support dietary advice.

\section{Key words: Dietary patterns: Meals: Factor analysis: Food intake}

Analysis of daily nutrient or food intake has traditionally been studied in nutritional research, but individuals do not consume these nutrients/foods separately; rather, food is consumed in a structured way by meals or snacks composed ${ }^{(1)}$ of a variety of foods, with complex combinations of nutrients that interact among themselves while facilitating or hindering the absorption of other nutrients ${ }^{(2,3)}$. To facilitate the understanding of dietary recommendations for populations, the $\mathrm{WHO}^{(4)}$ suggests that studies should be based on foods. This proposal was the source for appraisal studies referring to dietary pattern (DP), which are defined as sets of foods consumed by a specific population ${ }^{(5,6)}$. The number of studies using DP has increased in nutritional epidemiology, because it has the advantage of allowing the linkage of a complex network of foods to the disease outcome of the population ${ }^{(6-8)}$. The study of DP, using factor analysis, is generally performed by studying the diet as a whole ${ }^{(9-14)}$ but understanding that the nutritional composition of meals could complement current dietary advice. That is, the advice in the meal context might help by being more practical and salient to assist people to follow dietary guidelines ${ }^{(15)}$. Moreover, despite the fact that general DP are very important to understand the population's diet, it is not possible to identify characteristics specific of meals, and it additionally hinders the full understanding about which specific foods are interacting in a specific meal.
When people eat, it should have the meaning that they mainly choose to combine foods in the meals as per specific compositions, so that individuals of various cultures and different age groups give diverse significances to their meals ${ }^{(16)}$. In this way, the concept of a 'meal' can be useful for developing public policies and making it easier for the population to modify their meals instead of adopting new individual foods ${ }^{(17)}$. Thus, the meal-based approach could help in the dietary advice to assist populations in achieving the recommended daily intakes of foods and nutrients and daily meal preparation ${ }^{(15)}$.

Nevertheless, there are a few studies available that separately evaluate DP per meal, and when they do breakfast is the meal that is most commonly studied ${ }^{(18,19)}$; however, it must be taken into account that all meals are important ${ }^{(20)}$.

The purpose of this study was to identify the DP regarding breakfast, lunch and dinner of a population aged 20 years and older in Sao Paulo City.

\section{Methods}

\section{Design and study population}

Data came from the cross-sectional population-based survey entitled 'Health Survey of Sao Paulo' (ISA-Capital 2008), of

Abbreviations: $24 \mathrm{HR}, 24-\mathrm{h}$ recall; DP, dietary pattern.

*Corresponding author: R. O. Santos, fax: +55 113061 7705, email oliveira.ros@usp.br 
which a sample of the residents in the urban area of Sao Paulo City, Brazil was used ${ }^{(21)}$. Individuals aged 20 years and older, of both sexes and having data of food intake, were selected for this study ( $n$ 1102). The study was approved by the Committee of Ethics and Research of the School of Public Health of the University of Sao Paulo. This research was conducted according to the Declaration of Helsinki, and consent was obtained from all subjects.

\section{Dietary intake}

Trained interviewers directly gathered the data from the participants' homes at the time of the first 24-h recall (24HR) by using the multiple-pass method, and a second $24 \mathrm{HR}$ was performed telephonically, based on the computerised version called automated multiple-pass $\operatorname{method}^{(22,23)}$. The interviews were carried out over a 1-year period including weekdays, weekends and different seasons. The Nutrition Data System for Research software (version 2007, University of Minnesota) was used to obtain the nutritional information of the $24 \mathrm{HR}$, and the household measures reported were converted into units of weight or volume, as per the standardisation and quantification of the foods, and preparations were performed according to National publications ${ }^{(24,25)}$. A detailed verification of the entry data consistency was done, aimed at identifying possible errors and at correcting them.

\section{Definition of the meal}

During the application of the $24 \mathrm{HR}$, the interviewers asked the survey respondents to denominate each eating episode; they used the following question 'What name would you give to this meal?'. This question was used to specifically define the eating episode, following the criteria of being self-reported by the participant, and as was observed in other studies ${ }^{(26-29)}$. Any food or beverage that the participant had consumed during the denominated meal was considered. The individuals who did not mention the specific meal during the $24 \mathrm{HR}$ were classified as 'meal skipping'. Prevalence of meal skipping was calculated by taking into account the sample design. The sample expansion for the complex design as described by Sousa et al. ${ }^{(21)}$ was considered. The following meals were studied: breakfast, lunch and dinner.

\section{Dietary pattern assessment}

Food items from the $24 \mathrm{HR}$ were grouped according to the following criteria: nutritional value, intake habits of the Brazilian population, literature data and experience of the research team in other studies ${ }^{(30)}$. If a food item has sufficient intake in a specific meal, it was considered a food group itself. Afterwards the groupings were reclassified by taking into account three stages: first stage - exclusion or regrouping of the groups that did not provide information about two measures regarding at least one individual ${ }^{(31)}$ (this step was necessary because the Multiple Source Method (MSM) needs at least two short-term measurements for at least one individual); second stage exclusion of the food groups consumed by $<5 \%$ of the sample; and third stage - regrouping of the groups that showed a value $\leq 10 \%$ for the communality $\left(b^{2}\right)$ of the factor analysis, seeing that these items explain too little about the factors/patterns. When facing the impossibility of the regrouping, the groups/ foods items were excluded.

To estimate the usual individual intake of each food group and to attenuate the intrapersonal variability, the MSM (version 1.0.1, 2011, German Institute of Human Nutrition) was used; this is a statistical method developed to estimate the usual intake of nutrients and foods, both for populations and individuals $^{(31,32)}$.

The correlation matrix was calculated by considering all of the pairs of usual intakes of the food groups, and those groups that did not show significant correlations with any other groups were excluded from the analyses ${ }^{(6)}$. Thirteen groups were defined for breakfast, twenty-two groups for lunch and twenty groups for dinner (online Supplementary Data).

\section{Statistical analyses}

DP for each meal were derived from factor analysis (principal component estimation method) based on food group intakes. The food intake was evaluated according to grams, and the correlation matrix was used. The applicability of the data to the factor analysis was verified by using the Kaiser-Meyer-Olklin (KMO) and the Bartlett's sphericity test, considering acceptable the values over 0.50 and $P<0.05$, respectively ${ }^{(33,34)}$. The selection of the number of factors was primarily based on the latent root criterion, with eigenvalues over 1.0 and the Scree test analysis $^{(34)}$. Later on, the interpretation of each factor/pattern was considered, and after the choice of the number of factors, the communalities were observed, which reflect the level of linkage between the variable (food group) and the extracted factor $^{(35)}$. Those foods/groups of foods that showed a communality having a value $\leq 0 \cdot 10$ were excluded from the analysis, as they did not explain any factor. After the exclusion of the groups, factor analysis was performed again; it was decided to keep three factors for breakfast, four regarding lunch and four referring to dinner. The varimax orthogonal rotation was carried out in order to simplify the interpretation of the data, maximising the higher factor loadings and minimising the lower ones. The food groups having factor loadings (as per the analysis with the rotation) over 0.30 (in module) were considered as being representative of that pattern. The DP were denominated according to the food groups that stood out in each factor and/or considering the nomenclature used in previous studies about DP.

Statistical analyses were performed by using the Stata statistical package, version $10^{(36)}$

\section{Results}

\section{Study population}

The studied sample was primarily women (61.5\%), eutrophic $(55.9 \%)$, aged $20-97$ years with a mean age of $54(\mathrm{sD}=18.9)$ years, and $55.0 \%$ had per capita family income more than one minimum wage at the time of this study (approximately 217 US dollars). 


\section{Dietary patterns}

The prevalence of not having the meal was $5.6 \%$ for breakfast, $3.6 \%$ for lunch and $12.8 \%$ for dinner. The KMO values were over 0.5 , and the Bartlett's tests got $P<0.001$ for all meals, indicating that the data were correlated and that the factor analyses could be performed.

Regarding breakfast, the three DP explained $38.8 \%$ of the total variance. The first DP, called 'healthy', explained $14.3 \%$ of the variance and it showed significant contributions of the skimmed milk/semi-skimmed milk, whole-grain bread, white cheese and fruits, and negative factor loadings for whole milk, sugar and bread/toast, suggesting that the intake of these items shows a deviation from this DP. The 'traditional' DP showed a positive loading for coffee, sugar, butter/margarine and bread/ toast, and a negative one in regard to whole milk and milk with chocolate powder, and it explained $12.9 \%$ of the total variance; the 'snack' DP, which explained $11.7 \%$ of the total variance, pointed out a strong linkage to cold cuts, yellow cheese and bread/toast, and an inverse association with salted biscuits (Table 1).

Of the five lunch DP that were identified, the first one was called 'traditional' and it explained $8.4 \%$ of the total variance, being characterised by rice and beans and by negative loading for simple pasta. The 'salad' DP, characterised by the positive linkage to greens, salad dressing and natural condiments, explained $7.6 \%$ of the total variance. The 'sweetened juice' DP, which explained $6.6 \%$ of the variance, showed a strong bond to sugar and natural juice. The 'Western' DP was characterised by high loadings of alcoholic beverages, soft drinks, processed meats, sauces/mayonnaise, sweets and gnocchi/stuffed pasta, and it explained $6.0 \%$ of the total variance; finally, the 'meats' DP explained $5.5 \%$ of the variance, and it characterised itself by the preference for poultry meat, fish/seafood and eggs and a negative linkage to beef (Table 1).

The four DP, identified with dinner, explained $36.6 \%$ of the total variance. The 'coffee with milk and bread' DP explained $10 \cdot 2 \%$ of the total variance, and it was characterised by the positive correlation with coffee, bread/toast/biscuits, sugar and whole milk, and the negative bond to poultry meat. The 'Transition' DP explained $9.6 \%$ of the total variance, and it was characterised by foods both of the traditional DP and the Western ones, being positively correlated to beans, rice, eggs, processed meat, tubers/roots and sauces/mayonnaise, and negatively to soup/broth. The 'traditional' DP positively correlated to greens, salad dressing, natural condiments, rice, beef and beans, and negatively to simple pasta and sauces/mayonnaise, and it explained $9.4 \%$ of the total variance; finally, the 'soup and fruits' DP, which explained $6.9 \%$ of the total variance, showed a positive correlation to fruits and soup/broth, and a negative one to soft drinks and salted finger foods/pizza/ sandwiches.

\section{Discussion}

Similar DP were observed in the three studied meals: traditional, healthy and a pattern with foods rich in fats and sodium. However, at lunch and dinner appeared a fourth DP, which differed from those three patterns, and, at lunch, the fifth DP was composed of foods rich in protein. Thus, the analysis of DP according to meals allowed the identification of specific characteristics of each meal, such as a detailed combination of foods that are consumed in the meal and the prevalence of individuals skipping the meal. Moreover, this analysis allowed, for the first time, the identification of lunch and dinner patterns, which have no description in the scientific literature that generally grants more privilege to the breakfast, calling it the most important meal of the day ${ }^{(15,19,37)}$.

The 'traditional' DP of the breakfast showed a positive link to coffee, sugar, butter/margarine and bread/toast and a negative one to whole milk and milk with chocolate powder; these findings are similar to those of Siega-Riz et al. ${ }^{(38)}$, who identified bread and coffee as the foods that are most commonly consumed at breakfast, in addition to milk and breakfast cereals that showed an important intake in that meal.

Regarding lunch and dinner, the foods that characterised the meal as 'traditional' were the combination of rice and beans, and in dinner, in addition to these foods, the DP was characterised by greens, beef, salad dressings and natural condiments. This food combination is shown in most Brazilian studies about overall $\mathrm{DP}^{(10,12,14,39-43)}$. It is interesting to point out that the traditional DP of dinner comprises rice, beans, salads and beef, whereas for lunch the traditional pattern was just identified with rice and beans, a pattern for the salads and another one for the meats. In the study by Marchioni et $\mathrm{ll}^{(12)}$, the overall pattern called traditional was composed of rice, beans, pork meat, eggs, manioc, potatoes, corn, greens, lettuce, vegetable oil, sugar, meat, legumes, vegetables, roots and tubers; it is seen, within the foods, that findings are similar to the pattern of the same name found out in the dinner in our study. Similarities to the findings of the lunch were pinpointed by Marchioni et al. ${ }^{(40)}$ in the overall pattern denominated as traditional, composed of cereals and legumes.

Regarding the breakfast, the 'healthy' DP, which accounted for the highest proportion of the explained variance, was characterised by fruits, whole-grain bread, skimmed milk/semiskimmed milk and white cheese, and negative correlation to whole milk and bread/toast. In the lunch, the DP with foods that compose healthy patterns was the 'salad' DP (second highest proportion of the explained variance), and it was composed by greens, salad dressing and natural condiments. In the dinner, the 'soup and fruits' DP (fourth highest proportion of the explained variance) was composed of fruits and soup/broth and inverse relation to salted finger foods/pizza/sandwiches and soft drinks. This type of DP is compatible with the findings in other studies about overall DP, composed of foods being rich in fibres, such as fruits, greens and whole grains, and low content of fats referred to the skimmed dairy products and the non-fatty meats ${ }^{(9-11,44,45)}$

The DP known as 'Western' is mainly characterised by foods rich in fats, sugars and sodium, such as red meats, processed meats, sausage meats, soft drinks, sweets, among others $^{(9,11,14,42,46,47)}$. The 'snack' DP (cold cuts, bread/toast and yellow cheese) was revealed in the breakfast, and the 'Western' DP (sauces/mayonnaise, processed meats, sweets, soft drinks, alcoholic beverages and gnocchi/stuffed pasta) was thus 
Table 1. Factor loadings after rotation for the food groups of the patterns as identified for breakfast, lunch and dinner, for adults and elderly people in Sao Paulo City, 2008

\begin{tabular}{|c|c|c|c|c|c|c|c|c|c|c|c|c|}
\hline \multirow[b]{2}{*}{ Food groups } & \multicolumn{3}{|c|}{ Breakfast } & \multicolumn{5}{|c|}{ Lunch } & \multicolumn{4}{|c|}{ Dinner } \\
\hline & Healthy & Traditional & Snack & Traditional & Salad & $\begin{array}{l}\text { Sweetened } \\
\text { juice }\end{array}$ & Western & Meats & $\begin{array}{l}\text { Coffee with } \\
\text { milk and bread }\end{array}$ & Transitional & Traditional & $\begin{array}{l}\text { Soups } \\
\text { and fruits }\end{array}$ \\
\hline $\begin{array}{l}\text { Skimmed milk/semi- } \\
\text { skimmed milk }\end{array}$ & $0.66 \dagger$ & 0.04 & 0.02 & * & * & * & * & * & * & * & * & * \\
\hline Whole-grain bread & $0.58 \dagger$ & -0.08 & 0.08 & * & * & * & * & * & * & * & * & * \\
\hline White cheese & $0.41 \dagger$ & -0.07 & 0.10 & * & * & * & * & * & * & * & * & * \\
\hline Fruits & $0.37 \dagger$ & -0.21 & -0.03 & -0.18 & 0.15 & -0.08 & -0.15 & $0 \cdot 13$ & -0.12 & -0.05 & $-0 \cdot 10$ & $0.35 \dagger$ \\
\hline Whole milk & $-0.59 \dagger$ & $-0.37 \dagger$ & 0.13 & * & * & * & * & * & $0.56 \dagger$ & $-0 \cdot 13$ & -0.04 & 0.09 \\
\hline Sugar & $-0.38 \dagger$ & $0.49 \dagger$ & 0.03 & 0.12 & -0.05 & $0.81 \dagger$ & -0.05 & 0.01 & $0.58 \dagger$ & 0.11 & 0.03 & 0.05 \\
\hline Bread/toast & $-0.37 \dagger$ & $0.35 \dagger$ & $0.57 \dagger$ & * & * & * & * & * & * & * & * & * \\
\hline Coffee & -0.09 & $0.70 \dagger$ & -0.07 & * & * & * & * & * & $0.74 \dagger$ & -0.04 & -0.01 & 0.01 \\
\hline Butter/margarine & -0.23 & $0.41 \dagger$ & 0.20 & * & * & * & * & * & * & * & * & * \\
\hline Chocolate powders & -0.27 & $-0.62 \dagger$ & 0.06 & * & * & * & * & * & * & * & * & * \\
\hline Cold cuts & 0.09 & -0.14 & $0.71 \dagger$ & * & * & * & * & * & * & * & * & * \\
\hline Yellow cheese & 0.02 & -0.11 & $0.65 \dagger$ & * & * & * & * & * & * & * & * & * \\
\hline Salted biscuits & -0.14 & -0.22 & $-0.44 \dagger$ & * & * & * & * & * & * & * & * & * \\
\hline Rice & * & * & * & $0.81 \dagger$ & 0.06 & 0.03 & 0.00 & 0.01 & -0.25 & $0.64 \dagger$ & $0.44 \dagger$ & -0.04 \\
\hline Beans & * & * & * & $0.75 \dagger$ & -0.00 & 0.00 & -0.01 & -0.09 & $-0 \cdot 17$ & $0.68 \dagger$ & $0.34 \dagger$ & -0.06 \\
\hline Pasta & * & * & * & $-0.54 \dagger$ & $-0 \cdot 10$ & 0.08 & 0.07 & -0.17 & -0.18 & 0.20 & $-0.42 \dagger$ & $0 \cdot 16$ \\
\hline Greens & * & * & * & 0.05 & $0.80 \dagger$ & 0.01 & -0.06 & 0.12 & $-0 \cdot 18$ & 0.07 & $0.61 \dagger$ & 0.22 \\
\hline Salad dressing & * & * & * & 0.11 & $0.79 \dagger$ & -0.00 & -0.02 & 0.07 & -0.09 & 0.07 & $0.60 \dagger$ & 0.10 \\
\hline Natural condiments & * & * & * & -0.07 & $0.56 \dagger$ & 0.03 & 0.06 & -0.25 & -0.05 & 0.02 & $0.49 \dagger$ & 0.10 \\
\hline Natural juice & * & * & * & -0.08 & 0.05 & $0.75 \dagger$ & -0.06 & 0.04 & * & * & * & * \\
\hline Soft drinks & * & * & * & 0.05 & -0.06 & -0.15 & $0.53 \dagger$ & 0.02 & -0.16 & 0.01 & -0.10 & $-0.69 \dagger$ \\
\hline Alcoholic beverage & * & * & * & -0.01 & 0.06 & 0.11 & $0.49 \dagger$ & -0.27 & * & * & * & * \\
\hline Sweets & * & * & * & 0.03 & 0.01 & 0.11 & $0.38 \dagger$ & 0.16 & * & * & * & * \\
\hline $\begin{array}{l}\text { Gnocchi/stuffed } \\
\text { pasta }\end{array}$ & * & * & * & -0.20 & 0.01 & 0.06 & $0.36 \dagger$ & $0 \cdot 19$ & * & * & * & * \\
\hline Sauces/mayonnaise & * & * & * & -0.29 & 0.03 & 0.29 & $0.35 \dagger$ & 0.09 & -0.11 & $0.31 \dagger$ & $-0.42 \dagger$ & 0.27 \\
\hline Processed meat & * & * & * & 0.08 & -0.07 & -0.17 & $0.34 \dagger$ & 0.07 & 0.00 & $0.40 \dagger$ & -0.07 & 0.02 \\
\hline Eggs & * & * & * & 0.13 & -0.02 & 0.12 & $-0 \cdot 18$ & $0.36 \dagger$ & -0.02 & $0.43 \dagger$ & -0.09 & 0.16 \\
\hline Poultry meat & * & * & * & -0.01 & 0.07 & $0 \cdot 10$ & 0.05 & $0.34 \dagger$ & $-0.31 \dagger$ & -0.00 & 0.07 & 0.16 \\
\hline Fish/seafood & * & * & * & 0.08 & 0.02 & -0.08 & 0.17 & $0.33 \dagger$ & * & * & * & * \\
\hline Beef & * & * & * & 0.19 & 0.12 & 0.01 & 0.05 & $-0.71 \dagger$ & -0.08 & 0.15 & $0.39 \dagger$ & -0.12 \\
\hline Pork meat & * & * & * & 0.23 & -0.13 & 0.12 & 0.23 & -0.02 & * & * & * & * \\
\hline Industrialised juice & * & * & * & 0.14 & -0.07 & 0.11 & -0.25 & 0.08 & * & * & * & * \\
\hline Tubers/roots & * & * & * & 0.00 & 0.01 & 0.09 & -0.21 & -0.27 & -0.03 & $0.32 \dagger$ & 0.07 & 0.14 \\
\hline Bread/toast/biscuits & * & * & * & * & * & * & * & * & $0.68 \dagger$ & -0.14 & $-0 \cdot 18$ & 0.00 \\
\hline Soup/broth & * & * & * & * & * & * & * & * & -0.20 & $-0.55 \dagger$ & -0.04 & $0.34 \dagger$ \\
\hline $\begin{array}{l}\text { Salted finger foods/ } \\
\text { pizza/sandwiches }\end{array}$ & * & * & * & * & * & * & * & * & -0.12 & -0.28 & $-0 \cdot 17$ & $-0.65 \dagger$ \\
\hline $\begin{array}{l}\text { Percentage of } \\
\text { explained variance }\end{array}$ & $14 \cdot 3$ & $12 \cdot 9$ & $11 \cdot 7$ & 8.4 & $7 \cdot 6$ & $6 \cdot 6$ & $6 \cdot 0$ & 5.5 & $10 \cdot 2$ & $9 \cdot 6$ & $9 \cdot 4$ & $6 \cdot 9$ \\
\hline $\begin{array}{l}\text { Percentage of } \\
\text { accumulated } \\
\text { variance }\end{array}$ & $14 \cdot 3$ & $27 \cdot 2$ & 38.9 & 8.4 & $16 \cdot 0$ & $22 \cdot 6$ & $28 \cdot 6$ & $34 \cdot 1$ & $10 \cdot 2$ & $19 \cdot 8$ & $29 \cdot 2$ & $36 \cdot 1$ \\
\hline KMO & & 0.52 & & & & 0.54 & & & & 0.63 & & \\
\hline
\end{tabular}

KMO, Kaiser-Meyer-Olklin

* The food group was not included in the studied pattern.

$\dagger$ Loads $>0.30$ (in module).

identified in the lunch. However, for dinner, the 'transitional' DP was observed (rice, processed meats, eggs, beans, sauces/ mayonnaise and tubers/roots), which showed both foods that would be considered in the 'Western' DP and foods that define the 'traditional' DP. Vilela et al. ${ }^{(14)}$ identified a similar overall pattern, the 'regional traditional' one, characterised by refined grains and tubers, regional dishes (such as the 'feijoada' (Brazilian dish of beans cooked with dried meat, pork, sausages, etc.), fried bananas), meats and eggs, coffee, sugar, rice and beans.

The item that most explained the lunch was sugar $\left(b^{2}=0 \cdot 68\right)$, and the intake of this item has markedly increased along the past decades in the Western societies; it is considered as being a serious risk for the development of obesity ${ }^{(48)}$. According to the data of the 2008-2009 Research about Family Budgets, $61 \%$ of the Brazilian population showed an excessive consumption of free sugar (addition sugar plus the sugar contained in the juices) ${ }^{(49)}$. In this study, sugar was correlated to fruit juice defining the 'sweetened juice' DP of the lunch, being similar to the findings of Cavadini et al. ${ }^{(50)}$, who studied the diet of American teenagers, and they discovered a positive link between the intake of sugars and juices and a negative one between the intake of sugars and soft drinks, suggesting that sugars are added to the preparation of juices. 
The DP that accounted for the highest proportion of explained variance for dinner analysis was a typical DP of the Sao Paulo City breakfast ${ }^{(51)}$, the coffee with milk and bread pattern, characterised by coffee, sugar, bread/toast/biscuits and whole milk. In a global analysis of DP, it would be interpreted that those foods were ingested at breakfast ${ }^{(51)}$, as it is not possible to identify the meals that they were consumed. This pattern is an example of the benefit from the study of the DP by specific meal that could help public policies to promote healthier specific meals. Our findings indicated that at dinner there is a pattern that is typically consumed at breakfast and it is poor in fibres ${ }^{(51)}$; this practice must be discouraged.

The fifth and last DP, which was identified in the dinner, was 'meats', which was composed of poultry meat, fish/seafood and eggs, and it was inversely correlated to beef. From 2003 up to 2008, an increase in the intake of meats was identified in Sao Paulo City ${ }^{(52)}$, and in Brazil there was a $50 \%$ growth in the relative participation of the meats in the total of calories of the population food diet from 1974 up to $2003^{(53)}$.

This study revealed a $5.6 \%$ prevalence of skipping breakfast, and this value is below those identified in other studies ${ }^{(54-56)}$. Nicklas et al. ${ }^{(54)}$, in a cohort of young adults in an American city, reported that a $37 \%$ prevalence of not having breakfast was identified and the criteria used by the researchers to define such meal were the following: the breakfast had to contain a mixture of foods or a diet in which the values of the macro-nutrients were equal or surpassed the one of one glass of milk. It is evident that the type of definition chosen can significantly influence the results and interpretation of the studies in which they will be used ${ }^{(57)}$; thus, a consensus about the definition of the meals is needed in order to make the studies comparable.

Approximately $3.6 \%$ of the individuals skipped lunch and $12 \cdot 8 \%$ of them skipped dinner. Mostad et al ${ }^{(58)}$ reported a link between central obesity and low frequency of breakfast and lunch, and more frequent intake of snacks in the evening. The highest proportion of the persons who skipped dinner could be related to the methods that were used in the study, which considered the self-reported meals; in this manner, the individuals who had a snack in the evening and denominated it that way were not considered for the analysis of this meal. On the other hand, the studies that considered the intake hour could have gotten the snack as dinner.

The study of the DP, separately for each meal, allowed the identification of existing peculiarities for each meal, in addition to identifying the individuals who had not consumed them. It is a tool for surveys with the goal of analysing the quality and composition of the meals and identifying the problems that have an impact on the global patterns, as it identifies specific meal problems. Despite the fact it is a more complex analysis, the results separately by meals makes it easier to elaborate public policies. It is important that other studies perform the analysis of meals in other regions of the country, in order to provide more consistent subsidies for the implementation of more efficient public policies in Brazil. In addition to this, other studies are necessary to verify whether the DP per meal shows impacts over the health of the population as was previously made evident in other studies. The interrelations of a diet that is sometimes healthy and at other times less healthy, depending upon the meal being analysed, could bring data that have not been observed in literature, mainly because of the fact that overall analysis of DP may obscure complex meal patterns.

There are also limitations to the current study: the general limitation of statistical analysis that always stems from several subjective decisions that investigators must make - for example, the food grouping decision and the number of factors to be selected. Another limitation is the use of self-reported meal that may have influenced calculation of the prevalence of not having meals. As the definition of a meal is not well established in scientific literature, further discussion on this topic seems to be necessary. In addition, the short-term dietary assessment methods, that is, the $24 \mathrm{HR}$, provide more detailed information about types and amounts of food than long-term assessment methods ${ }^{59}$; however, they lead to a large within-person variation of dietary estimates. In that case, we highlight that the food group intake estimation was adjusted for the within-person variation through the MSM method and may have contributed to increase the reliability of the results. Principal strength is the innovation of this study, and to our knowledge it is the first article to study meal patterns.

\section{Acknowledgements}

The authors are grateful to the funding bodies for the financial support that enabled the development of this study.

This research was supported by the Health Department of the City of Sao Paulo, São Paulo Research Foundation (FAPESP process no. 2009/15831-0), and the National Council for Scientific and Technological Development (CNPq process no. proceeding 473100/2009-6). R. O. S. received a graduate student stipend from the Coordination for improvement of Higher Education Personnel (CAPES).

R. O. S. carried out the study and data analyses and drafted the manuscript, and contributed towards study concepts and design, and approved the final version of the manuscript submitted for publication. R. M. F. participated in the design and coordination of the study and acquisition of data. D. M. L. M. participated in the design and coordination of the study, the acquisition of data and helped in data analyses and drafted the manuscript. V. T. B. formulated the research questions and helped in data analyses and drafted the manuscript. All authors read and approved the final manuscript to be published.

The authors declare that they have no conflict of interests.

\section{Supplementary material}

For supplementary material/s referred to in this article, please visit http://dx.doi.org/10.1017/S0007114515002445

\section{References}

1. Oltersdorf U, Schlettwein-Gsell D \& Winkler G (1999) Assessing eating patterns - an emerging research topic in nutritional sciences: introduction to the symposium. Appetite 32, 1-7.

2. Newby PK \& Tucker K (2004) Empirically derived eating patterns using factor or cluster analysis: a review. Nutr Rev $\mathbf{6 5}$, 177-203. 
3. Olinto MTA (2007) Padrões alimentares: análise de componentes principais (Dietary patterns: principal component analysis). In Epidemiologia nutricional (Nutritional Epidemiology), pp. 213-225 [G Kac, R Sichieri and DP Gigante, editors]. Rio de Janeiro: Fio Cruz/Atheneu.

4. World Health Organization (1998) Obesity: Preventing and Managing the Global Epidemic. Technical Report Series no. 894. Geneva: World Health Organization.

5. Hoffman K, Schulze MB, Boeing H, et al. (2002) Dietary patterns: report of an international workshop. Public Health Nutr 5, 89-90.

6. Hu FB (2002) Dietary pattern analysis: a new direction in nutritional epidemiology. Nutr Metab 13, 3-9.

7. Messina M, Lampe JW, Birt DF, et al. (2001) Reductionism and the narrowing nutrition perspective: time for reevaluation and emphasis on food synergy. $J$ Am Diet Assoc 101, 1416-1419.

8. Jacob DR \& Steffen LM (2003) Nutrients, foods, and dietary patterns as exposures in research: a framework for food synergy. Am J Clin Nutr 78, 508S-513S.

9. Murtaugh MA, Herrick J, Sweeney C, et al. (2007) Diet composition and risk of overweight and obesity in women living in the southwestern United States. J Am Diet Assoc 107, $1311-1321$.

10. Gimeno SGA, Mondini L, Moraes AS, et al. (2011) Padrões de consumo de alimentos e fatores associados em adultos de Ribeirão Preto, São Paulo, Brasil: Projeto OBEDIARP (Dietary patterns and correlates in adults living in Ribeirão Preto, São Paulo State, Brazil: the OBEDIARP Project). Cad Saude Publica 27, 533-545.

11. Heidemann C, Scheidt-Nave C, Ricther A, et al. (2011) Dietary patterns are associated with cardiometabolic risk factors in a representative study population of German adults. Br J Nutr 106, 1253-1262.

12. Marchioni DM, Claro RM, Levy RB, et al. (2011) Patterns of food acquisition in Brazilian households and associated factors: a population-based survey. Public Health Nutr 14, 1586-1592.

13. Shin S \& Joung H (2013) A dairy and fruit dietary pattern is associated with a reduced likelihood of osteoporosis in Korean postmenopausal women. Br J Nutr 10, 1926-1933.

14. Vilela AAF, Sichieri R, Pereira RA, et al. (2014) Dietary patterns associated with anthropometric indicators of abdominal fat in adults. Cad Saude Publica 30, 502-510.

15. Leech RM, Worsley A, Timperio A, et al. (2015) Understanding meal patterns: definitions, methodology and impact on nutrient intake and diet quality. Nutr Res Rev 19, 1-21.

16. Andersson J, Nydahal M, Gustafsson K, et al. (2003) Meals and snacks among elderly self-managing and disabled women. Appetite 41, 149-160.

17. Wang WC, Worsley A \& Hodgson V (2012) Classification of main patterns - a latent class approach. Br J Nutr 109, 2285-2296.

18. Min C, Noh H, Kang Y, et al. (2012) Breakfast patterns are associated with metabolic syndrome in Korean adults. Nutr Res Pract 6, 61-67.

19. Yoo K, Suh H, Lee M, et al. (2014) Breakfast eating patterns and metabolic syndrome: the Korea National Health and Nutrition Examination Survey (KNHANES) 2007-2009. Asia Pac J Clin Nutr 23, 128-137.

20. Rogers PJ (1997) How important is breakfast? Br J Nutr $\mathbf{7 8}$, 197-198.

21. Sousa CA, César CLG, Barros MBA, et al. (2011) Prevalence of chronic obstructive pulmonary disease and risk factors in São Paulo, Brazil, 2008-2009. Rev Saude Publica 45, 887-896.
22. Raper N, Perloff B, Ingwersen L, et al. (2004) An overview of USDA'S dietary intake data system. J Food Compost Anal 17, 545-555.

23. Moshfegh AJ, Rhodes DG, Baer DJ, et al. (2008) The US Department of Agriculture automated multiple-pass method reduces bias in the collection of energy intakes. Am J Clin Nutr 88, 324-332.

24. Fisberg RM \& Villar BS (2002) Manual de receitas caseiras e medidas caseiras para cálculo de inquéritos alimentares: manual elaborado para auxiliar o processamento de inquéritos alimentares (Manual of Recipes and Household Measures for Dietary Surveys Calculation: Manual Prepared to Assist Processing of Dietary Surveys). São Paulo: Signus.

25. Pinheiro ABV, Lacerda EMA, Benzecry EH, et al. (2008) Tabela para avaliação de consumo alimentar em medidas caseiras (Table for Evaluation of Food Consumption in Household Measures), 5th ed. São Paulo: Atheneu.

26. Bellisle F, Dalix AM, Mennen L, et al. (2003) Contribution of snacks and meals in the diet of French adults: a diet-diary study. Physiol Behav 79, 183-189.

27. Kant AK, Andon MB, Angelopoulos TJ, et al. (2008) Association of breakfast energy density with diet quality and body mass index in American adults: National Health and Nutrition Examination Surveys, 1999-2004. Am J Clin Nutr 88, 1396-1404

28. Deshmukh-Taskar PR, Radcliffe JD, Liu Y, et al. (2010) Do breakfast skipping and breakfast type affect energy intake, nutrient intake, nutrient adequacy, and diet quality in young adults? NHANES 1999-2002. J Am Coll Nutr 29, 407-418.

29. Kant AK, Graubard BI \& Mattes RD (2012) Association of food form with self-reported 24-h energy intake and meal patterns in US adults: NHANES 2003-2008. Am J Clin Nutr 96, 1369-1378

30. Selem SSC, Castro MA, César CLG, et al. (2014) Associations between dietary patterns and self-reported hypertension among Brazilian adults: a cross-sectional populationbased study. I Acad Nutr Diet 114, 1216-1222.

31. European Food Consumption Validation Project (2011) Multiple Source Method (MSM) for estimating usual dietary intake from short-term measurement data: user guide. https:// msm.dife.de/ (accessed September 2014).

32. Haubrock J, Nöthlings U, Volatier JL, et al. (2011) Estimating usual food intake distributions by using the multiple source method in the EPIC-Potsdam Calibration Study. J Nutr 141, 914-920.

33. Kaiser HF (1974) An index of factor simplicity. Psychometrika 39, 31-36.

34. Hair JF, Black W, Babin BJ, et al. (2009) Análise multivariada de dados (Multivariate Data Analysis: Cluster Analysis), 6th ed. Porto Alegre: Bookman; Análise de agrupamento.

35. Figueiredo Filho DB \& Silva Júnior JA (2010) Visão além do alcance: uma introdução à análise fatorial (Vision beyond the range: an introduction to factor analysis). Opin Pública 16, 160-185.

36. StataCorp (2007) Stata Statistical Software: Release 10. College Station, TX: StataCorp LP.

37. Deshmukh-Taskar P, Nicklas TA, Radcliffe J, et al. (2012) The relationship of breakfast skipping and type of breakfast consumed with overweight/obesity, abdominal obesity, other cardiometabolic risk factors and metabolic syndrome in young adults. The National Health and Nutrition Examination Survey (NHANES): 1999-2006. Public Health Nutr 16, 2073-2082.

38. Siega-Riz AN, Popkin BM \& Carson T (2000) Differences in food patterns at breakfast by sociodemographic characteristics 
among a nationally representative sample of adults in the United States. Prev Med 30, 415-424.

39. Sichieri R (2002) Dietary patterns and their associations with obesity in the Brazilian city of Rio de Janeiro. Obes Res $\mathbf{1 0}$, 42-48.

40. Marchioni DML, MRDO Latorre, Eluf-Neto J, et al. (2005) Identification of dietary patterns using factor analysis in an pidemiological study in São Paulo. Med J 123, 124-127.

41. Neumann AICP, Martins IS, Marcopito LF, et al. (2007) Padrões alimentares associados a fatores de risco para doenças cardiovasculares (Dietary patterns associated with risk factors for cardiovascular disease in a Brazilian city). Rev Panam Salud Publica 22, 329-339.

42. Cunha DB, RMVR Almeida \& Pereira RA (2010) A comparison of three statistical methods applied in the identification of eating patterns. Cad Saude Publica 26, 2138-2148.

43. Nascimento S, Barbosa FS, Sichieri R, et al. (2011) Dietary availability patterns of the Brazilian macro-regions. Nutr J 10, 1-8.

44. Akter S, Nanri A, Yi S, et al. (2012) Dietary patterns and C-peptide concentrations in a Japanese working population. Nutrition 28, 29-35.

45. Zeng F, Wu B, Fan F, et al. (2013) Dietary patterns and risk of hip fractures in elderly Chinese: a matched case-control study. J Clin Endocrinol Metab 98, 2347-2355.

46. Hu FB, Rimm EB, Stampfer MJ, et al. (2000) Prospective study of major dietary patterns and risk of coronary heart disease in men. Am J Clin Nutr 72, 912-921.

47. Fung TTF, Willet WC, Stampfer MJ, et al. (2001) Dietary patterns and the risk of coronary heart disease in women. Arch Intern Med 161, 1857-1862.

48. Malik VS, Willet WC \& Hu FB (2013) Global obesity: trends, risk factors and policy implications. Nature $\mathbf{9}, 13-27$.

49. Instituto Brasileiro de Geografia e Estatística (2010) Pesquisa de orçamentos familiares, 2008-2009. Análise do consumo alimentar pessoal no Brasil (National Household Budget
Survey 2008-2009. Analysis of the personal food intake in Brazil). Rio de Janeiro: IBGE.

50. Cavadini C, Siega-Riz AM \& Popkin BM (2000) US adolescent food intake trends 1965 to 1996. Arch Dis Child 83, 18-24.

51. Mattos LL \& Martins IS (2000) Consumo de fibras alimentares em população adulta (Dietary fibre consumption in an adult population). Rev Saude Publica 34, 50-55.

52. de Carvalho AM, César CLG, Fisberg RM, et al. (2014) Meat consumption in São Paulo - Brazil: trends in the last decade. PloS ONE 9, e96667.

53. Levy-Costa RB, Sichieri R, Pontes NS, et al. (2005) Disponibilidade domiciliar de alimentos no Brasil: distribuição e evolução (1975-2003) (Household food availability in Brazil: distribution and trends (1975-2003)). Rev Saude Publica 39, 530-540.

54. Nicklas TA, Myers L, Reger C, et al. (1998) Impact of breakfast consumption on nutritional adequacy of the diets of young adults in Bogalusa, Louisiana: ethnic and gender contrasts. J Am Diet Assoc 98, 1432-1438.

55. Ministry of Health and Welfare \& Korea Centers for Disease Control and Prevention (2008) National Health Statistics. Seoul: KCDC.

56. Haire-Joshu D, Schwarz C, Budd EL, et al. (2011) Postpartum teens' breakfast consumption is associated with snack and beverage intake and body mass index. J Am Diet Assoc 111, 124-130.

57. Gatenby SJ (1997) Eating frequency: methodological and dietary aspects. Br J Nutr 77, 7-20.

58. Mostad IL, Langaas M \& Grill V (2014) Central obesity is associated with lower intake of whole-grain bread and less frequent breakfast and lunch: results from the HUNT study, an adult all-population survey. Appl Physiol Nutr Metab 34, 1-10.

59. Tucker KL (2007) Assessment of usual dietary intake in population studies of gene-diet interaction. Nutr Metab Cardiovasc Dis 17, 74-81. 